\section{Doctors from different schools vary in later postgraduate exams}

\section{Susan Mayor LONDON}

Graduates from some UK medical schools consistently perform better than others in postgraduate medical exams, says a study published this week. The authors say that their finding supports the introduction of a national licensing examination for doctors.

The study retrospectively analysed the performance from 2003 to 2005 of 5827 doctors from 19 UK medical schools in one or more of the three examinations required for membership of the Royal College of Physicians. This is an international postgraduate assessment that is important for career progression and is attempted by about $30 \%$ of all UK medical graduates.

The research group looked at performance in parts 1 and 2 of the written examination, which are multiple choice assessments, and in part 2 of the practical examination of clinical assessment skills (PACES), which uses real and simulated patients to test clinical examination and communication skills. A further analysis involved data on performance in the part 1 examination over a much longer timeframe, from 1989 to 2002.

The results showed that graduates from Oxford, Cambridge, and Newcastle upon Tyne performed significantly better than average in part 1 and part 2 of the written examination (BMC Medicine 2008;6:5). Those from Liverpool, Dundee, Belfast, and Aberdeen showed significantly below average performance. Ninety one per cent of Oxford students, 76\% from Cambridge, and $67 \%$ from Newcastle passed part 1 at their first attempt, whereas the figures were $32 \%$ for Liverpool, 38\% for Dundee, 37\% for Belfast, and $41 \%$ for Aberdeen.

The overall relation between medical school and exam performance was highly significant $\left(\chi^{2}=300, \mathrm{df}=6, \mathrm{P}<0.001\right)$.

About $60 \%$ of the variance between medical schools was explained by differences in pre-admission qualifications (according to number of points gained, but not subjects taken, in A level examinations or in the Scottish highers). However, the remaining portion of the variance was still significant.

\title{
Coronary artery disease in US may no longer be declining
}

Janice Hopkins Tanne NEW

YORK

The US decline in coronary artery disease may have ended in the mid 1990s and the disease may even be increasing, reports an unusually comprehensive autopsy study from the Mayo Clinic and the University of British Columbia. "Our finding that temporal declines in the grade of coronary artery disease at autopsy have ended, together with suggestive evidence that declines have recently reversed, provides some of the first data to support increasing concerns that declines in heart disease mortality may not continue," the authors write.

A possible reason may be the recent epidemics of obesity and diabetes, which began at about the time when coronary artery

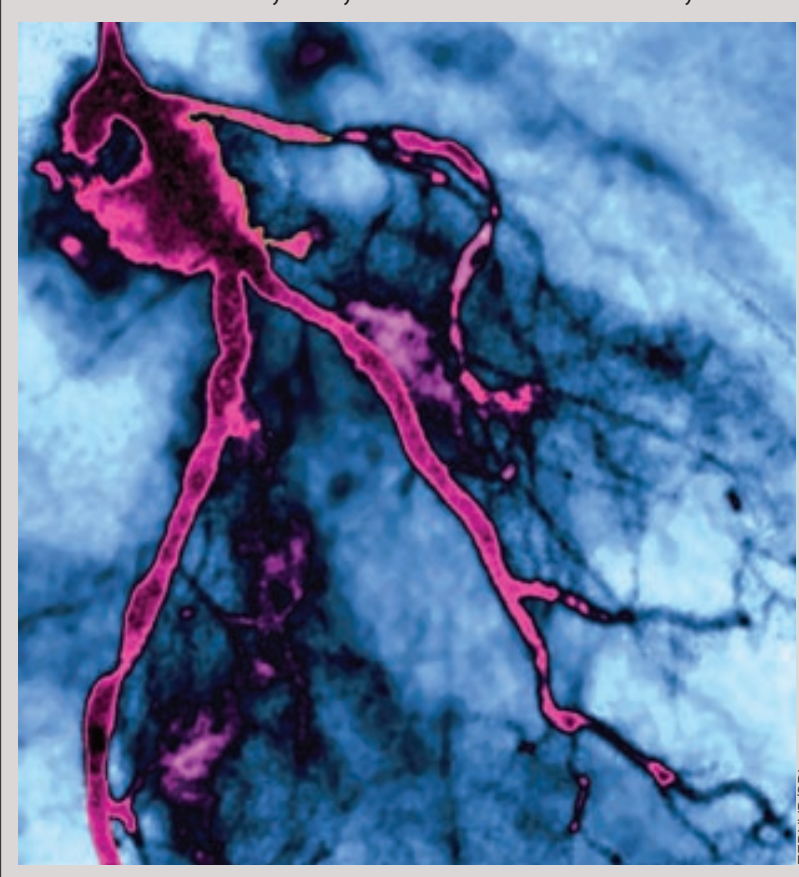

Autopsies showed coronary artery disease stopped declining in 1995 adjusted for the individuals' age and sex showed declines during the study period in high grade disease, the average grade of disease, and any disease. The decline was consistent with the national decline in self reported myocardial infarctions in data up to 1994.

In this study, however, the authors write, "among these non-elderly individuals... declines in the grade of coronary artery disease ended after 1995, and there is suggestive evidence that the grade of coronary artery disease may have increased since 2000."

Although the autopsy rate in the US is a low $8.3 \%$, Olmsted County has always had a higher rate. The county has a population of about 125000 and is predominantly white. All autopsies were done at the Mayo Clinic's pathology department.

In an accompanying editorial, Drs Jay Olshansky and Victoria Persky of the University of Illinois at Chicago write that previous studies had shown that incidence and mortality from coronary artery disease in the United States and in Olmsted County had declined through the 1980s and 1990s, though declines were smaller in the 1990s. The current study may show a reversal in the trend towards decline (Arch Intern Med 2008;168:261).

"If so, the reversal in trends in young adults could precede that in older individuals in the future. 


\section{Parents are sentenced to prison for not vaccinating children}

Ned Stafford HAMBURG

Two sets of parents in Belgium who refused to have their children vaccinated against polio, which is compulsory under Belgian law, were convicted earlier this month. Each parent was fined $€ 5500$ (£4100; \$8000) and sentenced to five months in prison.

In an interview with the $B M J$ the presiding judge, Bart Meganck of the Court of First Instance in the Flemish city of Dendermonde, said that the parents failed to appear for the 4 February court date. He therefore convicted them on the basis of police reports. He suspended the prison sentences pending whether or not the children receive polio vaccinations.

Asked what would happen if the parents still refuse, Judge Meganck said: "I don't think that will happen." He explained that if they fail to obey the court then that would be a "new crime" and they would receive a new summons to appear in court.

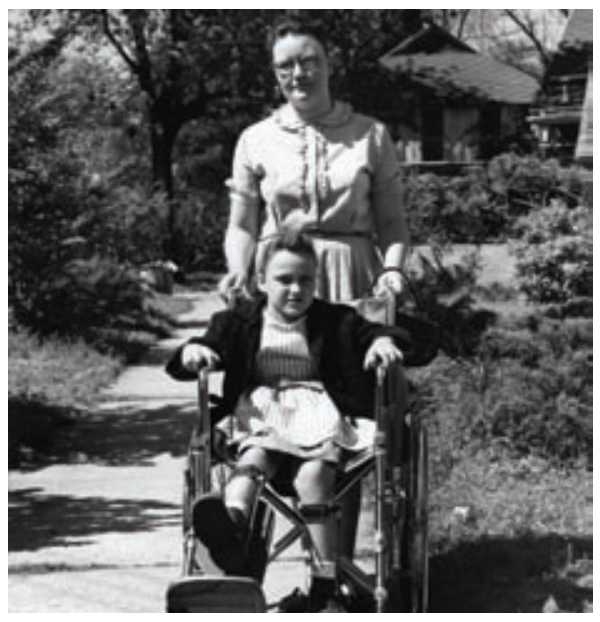

Pictures like this were used to encourage US parents to vaccinate their children in the 1950 s
Since the late 1960 s vaccination against polio has been compulsory in Belgium for all infants before they reach 18 months old. It is the only vaccine that is compulsory. The doctor administering the vaccination gives parents a document of proof, which must then be presented to local officials in the community where the child was born. If parents fail to meet the 18 month deadline, Judge Meganck said, they are reminded by local officials. If they still refuse, the district attorney is notified.

Roland Lemye, president of the Belgian Medical Association, said that he supports compulsory polio vaccination. "Usually I believe in individual freedoms," he said. "But we need polio vaccinations to protect the children and the population. Polio is a very serious disease."

Because of privacy laws Judge Meganck could not say how many children were involved in the current court case, their ages, or the motivation of the parents for refusing polio vaccination.

From the date the parents receive official notification of their convictions they have 15 days to ask for a new hearing in Judge Meganck's court, allowing them to appear this time with legal representation and to testify. The parents also have the option to appeal the conviction directly at the provincial level, he said.

"It would be better for them to come back to me and appear," Judge Meganck said. This would allow the parents to explain their motivation for refusing the vaccinations. But he noted that Belgian law allows exceptions only if parents can prove that the child might have adverse health reactions to the polio vaccine.

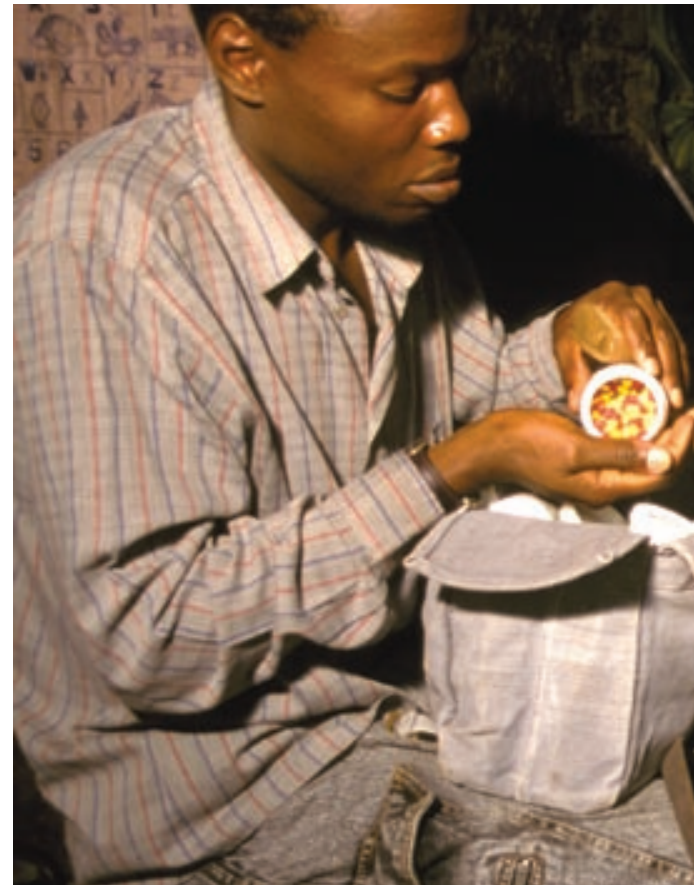

\section{Ugandan patients don't get the AIDS drugs they need}

\section{Henry Wasswa KAMPALA}

The number of Ugandans with AIDS who are being treated with antiretroviral drugs is now 110000 , but health authorities say that more than twice that number should be receiving them.

"We have about one million people with AIDS in the country," said Emmanuel Otala, Uganda's minister for primary health care, last week. "A total of 250000 deserve to be put on the ARVs [antiretrovirals] because their CD4 count has reduced to below 200 . Of these, so far there are only 110000 on the drugs, and we have a deficit of 140000 who would otherwise be on the ARVs. The

\section{French doctors are tried for treating children with infected}

Brad Spurgeon PARIS

Seven doctors and pharmacists went on trial in France last week over the death of at least 110 people who became infected with CreutzfeldtJakob disease after being given tainted human growth hormone when they were children.

The United States, Britain, and other countries halted the distribution of growth hormone in 1985, after it was discovered that three people had died after being given the product. Growth hormone at that time was extracted from pituitary glands removed from corpses. The cause of some subsequent deaths was CreutzfeldtJakob disease.

Doctors in France, however, continued to use the hormone for severalyears, treating thousands of children, before turning to a synthetic substitute in 1988 (BMJ 1997;314:165).

After the first death in France was recorded in 1991 the family took to court the company responsible for collecting the pituitary glands, France-Hypophyse, along with the Pasteur Institute, which prepared the treatment, and the Pharmacie Centrale des Hôpitaux de Paris, which distributed the treatment.
Some 250 people have taken out lawsuits, and the hearing is expected to last until 31 May. The defendants are charged with "involuntary homicide" and "aggravated deception." Six of them risk up to fouryears in prison and fines of up to $€ 150000$ ( $£ 112000$; \$218000), while the seventh, Fernand Dray, formerly of the Pasteur Institute, also faces charges of corruption and up to 10 years in prison. 


\section{IN BRIEF}

Nigeria files for extradition of drug trial officials: The government of Kano, a state in northern Nigeria, has filed a petition for the extradition of three US based employees of Pfizer-Scott Hopkins, Deborah Williams, and Michel Dunneto-to face criminal charges stemming from a study with the antibiotic trovafloxacin (Trovan) during a meningitis epidemic in Kano in 1996.

\section{Supermarket chain to open clinics} in US stores: Wal-Mart will open clinics staffed by nurse practitioners and physician assistants in some of its supermarkets from April this year. They will be run as joint ventures with local hospitals in Atlanta, Georgia; Dallas, Texas; and Little Rock, Arkansas. The development may be one response to a shortage of primary care doctors in the US (BMJ 2008;336:305).

Heart transplants fall in UK: The number of heart transplants has declined over the past decade in the United Kingdom and is now below the rates in Europe and the United States. The rate dropped from 5.2 per million population in 1995-9 to 2.9 in 2003-7. This compares with 4.4 in Europe and 7.0 in the US. The median age of donors has increased from 33 to 38 . The reduction is in part because of fewer trauma donors in recent years (Vournal of Heart and Lung Transplantation 2008;27(suppl 1):S122).

\section{Rate of antidepressant prescribing} unrelated to suicide rate: The rate of prescribing of antidepressants is not associated with suicide, according to a study based on data for England Uournal of Public Health 2008 Jan 31; doi: 10.1093/pubmed/fdm085). Between 1993 and 2004, age standardised rates for suicide fell from 98.2 to 81.3 per million population, and antidepressant prescribing fell from 9.2 to 7.4 per million population. The authors concluded that prescribing of antidepressants was not associated with deaths from suicide or poisoning by antidepressants.

\section{GPs get course in sexual health: The} Royal College of General Practitioners is launching a new two part introductory certificate in sexual health for GPs who want to increase their confidence and skills in dealing with sexual health in routine practice. The first part of the course, an e-module, is scheduled go live at the end of March, followed by face to face training sessions in July and October. For more details email Russell Fleet (rfleet@medfash.bma.org.uk).

\section{Patients face long waits for audiology}

\section{Owen Dyer LONDON}

A report from the Royal College of Physicians criticises the audiological and audiovestibular care provided by the NHS in the United Kingdom, and it calls for more integrated services and the rapid training of more specialists.

Waiting times for audiology services can be long, despite recent improvements, and patients are often treated by specialists in other disciplines, particularly by ear, nose, and throat (ENT) specialists, the report has found. The NHS does not track waiting times for many audiological treatments, but the most recent data, from December 2006, showed 166740 patients awaiting audiology assessments, with roughly two thirds waiting more than 13 weeks.

"Research suggests that patients with quite routine vestibular disorders often aren't getting a proper diagnosis until their third or fourth doctor's visit," said Linda Luxon, professor of audiological medicine at the University of London's Institute of Child Health, and the principal author of the report. "That represents a huge waste of resources," she added.

Hearing and balance disorders have traditionally been a low priority for the NHS, yet they add up to

\section{Home Office rules will cut postgraduate training applications}

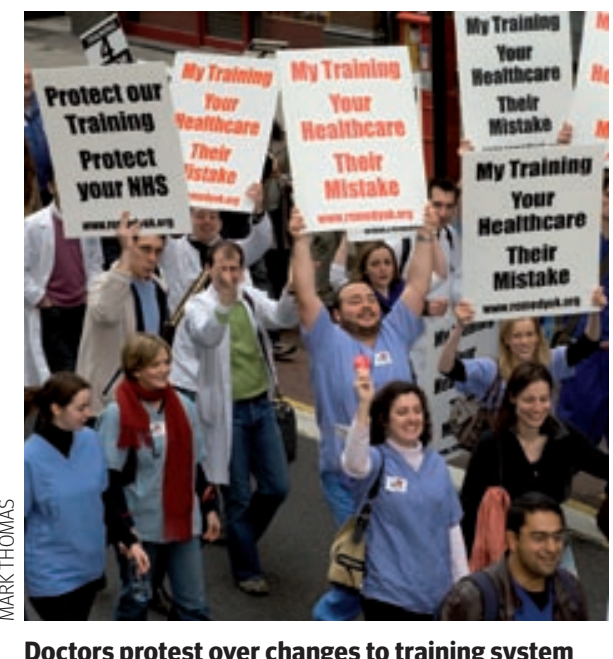

\section{Adrian O'Dowd MARGATE}

The government has announced new temporary immigration regulations that will bar doctors from beyond the European Union from gaining postgraduate medical training places in the United Kingdom.

The new Home Office rules will prohibit foreign doctors from taking training posts in the UK by applying through the highly skilled migrant programme, the traditional route to take up a post offered without a work permit.

The regulations are temporary until the Department of Health decides whether or not to implement its own guidance which gives priority to doctors trained in the UK. At present, this guidance is subject to consideration by the House of Lords, a three month consultation exercise, and an equality impact assessment.
The Department of Health said last week that the Home Office's changes would reduce the potential pool of migrants applying to UK postgraduate medical training from 5000 to 3000 in 2009. Doctors who currently have highly skilled migrant status will be able to apply for training posts this year.

The Home Office's immigration rules implement the first part of a new points based system, which is the general route for highly skilled migrants that will replace the existing programme and take effect from 29 February.

The health secretary, Alan Johnson, said that the UK was not closing the door to international doctors working in the NHS.

"Doctors from overseas have played an invaluable role in the NHS for many years and will continue to do so," he said.

"They have helped us fill key shortage areas such as psychiatry, obstetrics and gynaecology, and paediatrics. [But] it can cost up to $£ 250000$ (€350000; $\$ 500000$ ) to train a UK medical student, and, with the increase in UK medical schools, we are moving to a policy of self sufficiency."

Ramesh Mehta, president of the British Association of Physicians of Indian Origin, welcomed the move, saying, "This is a step in the right direction.

"This step should have been taken four or five years ago."

Hamish Meldrum, the BMA's chairman, said, "This is a confusing move, which seems to achieve little apart from adding to the uncertainty for overseas doctors in the NHS."

In the long term, the Department of Health wants to implement guidelines that say international medical graduates could only be considered for applications if there were no suitable UK or EU applicant. The Department of Health's consultation paper is at. www.mmc.nhs.uk 


\section{services and treatment by non-specialists}

a considerable burden of disability. Disorders of the ear represent $24 \%$ of all disabilities in the UK adult population. Among adults aged $18-60,17 \%$ have substantial hearing loss, and the prevalence is far higher in elderly people.

The newborn hearing screening programme, implemented fouryears ago, has found hearing impairment in early childhood to be $50 \%$ more common than previously thought. About one child in 1000 is born with permanent loss of hearing.

The government has tried to improve hearing services in recentyears, most visibly through the modernising hearing aid services programmes for adults and children, Professor Luxon said. "This has been a real success, but, still, fewer than half of those who would benefit from hearing aids have them."

Audiovestibular services have lagged further behind. The UK has only 42 audiovestibular specialists, fewer than one per million population. This compares with one per 135000 in Sweden and one per 125000 in Denmark.

The report recommends that five new training numbers be funded each year for the next five years. Given expected retirements, this would produce roughly 200 audiovestibular specialists by 2016 , or one per 300000 population.
The report also recommends that GPs receive audiovestibular training. Regions should be served by multidisciplinary teams based at hospitals.

Hearing and Balance Disorders: Achieving Excellence in Diagnosis and Management is available from www. rcplondon.ac.uk/pubs priced $\mathbf{f 2 0}$.

Disorders of the ear account for $\mathbf{2 4 \%}$ of disabilities in the UK adult population

\section{BMA advises GPs on longer opening hours}

\section{Zosia Kmietowicz LONDON}

GPs' leaders last week appeared to have given in to government pressure to extend the opening hours of general practices. In a letter to GPs ahead of a poll this month to gauge attitudes to the changes to their contract the BMA's General Practitioners Committee advises members that accepting the latest offer will be better than having a tougher deal imposed on them in April.

Under the deal GPs' surgeries would be open for an additional 30 minutes per week per 1000 registered patients, in blocks of 1.5 hours after $630 \mathrm{pm}$ or for 1 hour before 8 am or on a Saturday morning. The

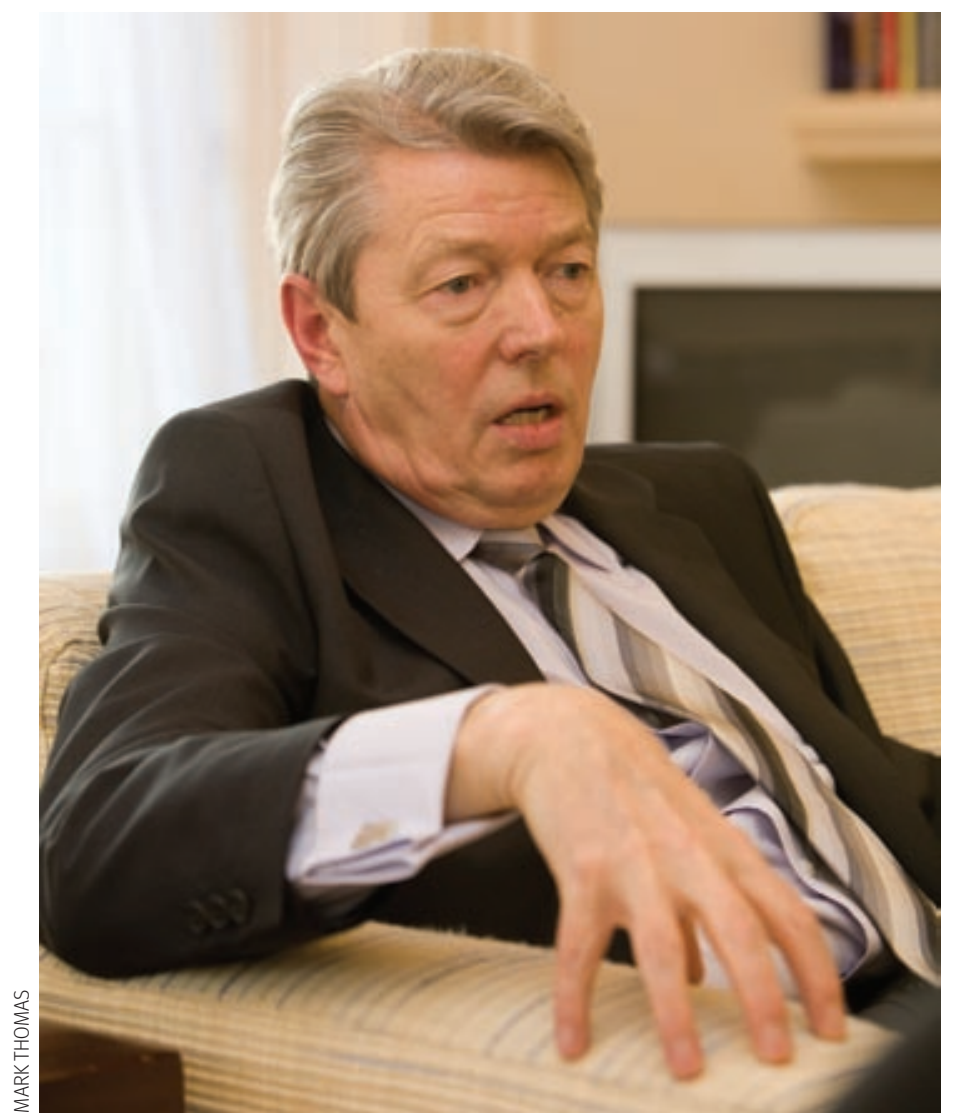

Health secretary Alan Johnson said he hoped GPs would accept option A extended hours will be funded by redirecting $£ 158 \mathrm{~m}(€ 210 \mathrm{~m}$; $\$ 310$ ) from the 2007-8 contract together with an extra 1.5\% uplift in the value of the contract.

The alternative contract, which the government would impose in the event of GPs not accepting the deal offered, would have opened up the way for private providers, according to the BMA, as the money for increasing access would be transferred to primary care trusts. The BMA said that practices would stand to lose 135 quality and outcomes framework (QOF) points, which together with a loss of access payments would cost a practice of 6000 patients $£ 35000$ a year.

Laurence Buckman, chairman of the General Practitioners Committee, said the decision to issue the latest advice on the deal was "because the alternative option will harm the underlying fabric of NHS general practice and patient care more quickly and more lastingly."

A letter sent last week to the committee from NHS Employers, the organisation responsible for employment procedures in the NHS, helped the committee reach its consensus. It led to "clarification" about the deal that made the wording "less prescriptive" and "easier for GPs to see how they might be able to offer extended hours," said Dr Buckman.

"This is neither a climbdown nor a $U$ turn but a recognition that between two bad alternatives one is worse than the other," he said. "The two deals on the table from the government haven't been negotiated; they are inflexible and do not take into account the differing needs of populations around the UK. It's this method of 'negotiation' that has angered GPs, and it's why we felt we couldn't accept anything without first consulting the profession.

"We have been studying the detail of the two impositions and have provided GPs with our analysis. We still have huge concerns that patients will get neither a meaningful service in extended hours nor the quality ... they deserve."

After the BMA announced that it was writing to GPs, health secretary Alan Johnson said: "The final decision rests with GPs and I hope that they will accept option A because we have the same objective of improving patient care and enhancing even further our world class primary care in the UK." 


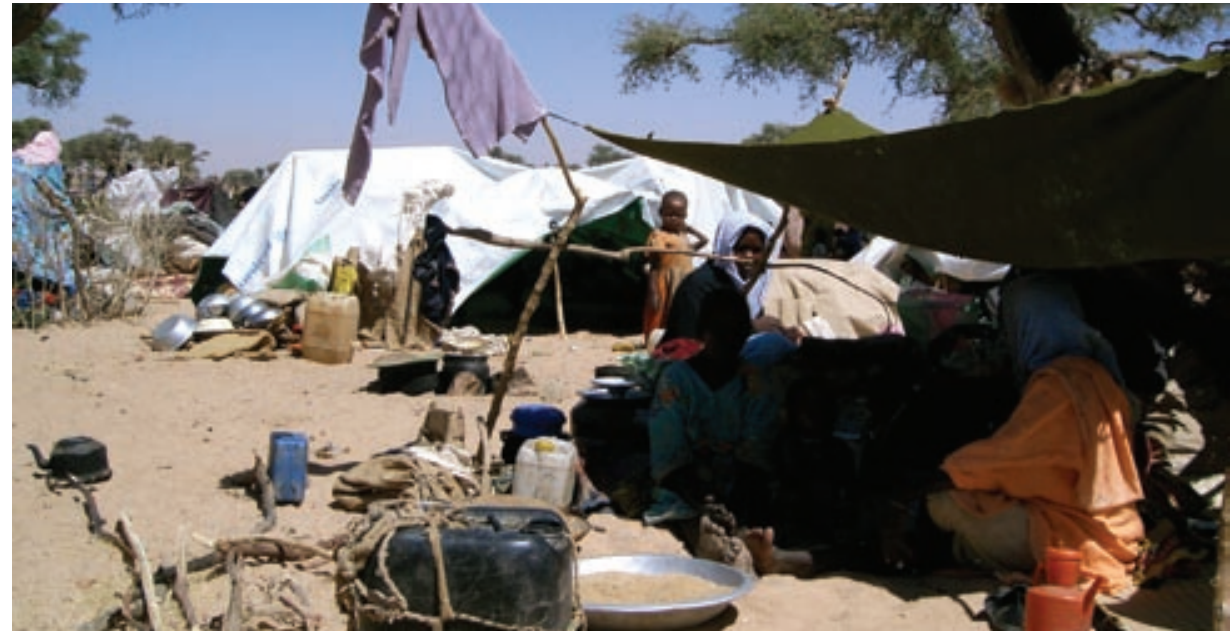

Children and mothers take shelter at a Unicef camp in northern Darfur

\section{Unicef seeks $\$ 900 \mathrm{~m}$ for children and women affected by 39 emergencies}

\section{John Zarocostas GENEVA}

Health and nutrition loom large in Unicef's 2008 emergencies appeal, launched last week. The agency is calling for donors to provide $\$ 856 \mathrm{~m}$ (£440m; €590m) to help the children and women who are victims of 39 current emergencies around the world, the vast majority of which are in sub-Saharan Africa.

"Children and women continue to bear the brunt of conflict and displacement," said Hilde Johnson, Unicef's deputy executive director, at a press conference in Geneva.

In a foreword to the organisation's action report for this year, Ann Veneman, Unicef's executive director, writes: "We count on the continued support and generosity of our donors to help ensure the survival, protection and well-being of women and children in these emergency situations."

In many of the world's trouble spots, including Sudan, Somalia, and the Democratic Republic of Congo, Unicef is seeking large amounts of new funds to help the millions of people who continue to suffer.

In Sudan Unicef is seeking $\$ 150 \mathrm{~m}$ for 2008 , including $\$ 37 \mathrm{~m}$ for health and nutrition and $\$ 5 \mathrm{~m}$ for HIV and AIDS programmes. Health requirements for northern Sudan and the three states of Darfur include programmes to provide measles vaccination and vitamin A supplementation to 3.9 million children.

It also hopes to provide 1.9 million women of child bearing age with three doses of tetanus toxoid and one million Darfurian children aged under 5 years with two rounds of polio vaccination.

Similarly, in Somalia, Unicef says, it needs
$\$ 22 \mathrm{~m}$ for health and nutrition, by far the biggest item of the $\$ 47 \mathrm{~m}$ sought from donors for the country. The funds are urgently needed to provide interventions such as measles vaccination, deworming, vitamin A supplements, and oral rehydration for 350000 children aged under 5 .

For the Democratic Republic of Congo the agency is seeking $\$ 106 \mathrm{~m}$, of which about a third is for health and nutrition $(\$ 35 \mathrm{~m})$. It is seeking \$2m for AIDS programmes there. High on Unicef's priorities for the country is to procure and distribute essential drugs and equipment to 300 health centres and to provide drugs and operational support in response to cholera and meningitis outbreaks.

In other regions, Unicef is seeking $\$ 19 \mathrm{~m}$ for North Korea, including $\$ 8 \mathrm{~m}$ for health and nutrition. It aims to fund the procurement and distribution of essential drugs to more than 2000 health facilities covering more than 10 million people.

The agency's health and nutrition needs for South Asian nations include $\$ 2.2 \mathrm{~m}$ for Afghanistan and $\$ 35 \mathrm{~m}$ for neighbouring Pakistan.

The requirements for Afghanistan include the distribution of essential emergency drugs and equipment to 200000 people, particularly internally displaced persons, says the agency.

Priorities for Pakistan, says Unicef, include ensuring that at least 400000 people have access to primary healthcare services through health facilities and community based outreach services. The agency states that it intends to construct 50 basic health units and five slightly larger rural health centres. Unicef's Humanitarian Action Report 2008 is available at www.unicef.org.

\section{Industry's push to woo nurses has been helped by journals}

\section{Michael Day MILAN}

Nursing journals are aiding and abetting the drug industry's attempts to influence nurses' prescribing, it has been claimed this week.

A report in PloS Medicine (2008;5:e5 doi: $10.1371 /$ journal.pmed.0050005) notes that nurses now have greater power to choose products and services and to influence choices made by doctors and other clinical colleagues. As a result, say the New Zealand authors, Annemarie Jutel of Otago Polytechnic and David Menkes of the University of Auckland, nurses are now a "desirable target" for the industry.

However, they say, although medical journals have often criticised drug companies for exploiting patients and doctors through techniques such as direct to consumer advertising, ghost writing, gifts, and free meals, the nursing literature "has yet to pay much attention" to the issue.

To study the industry's relationship with the nursing press the authors searched nursing journals in two leading clinical news databases, MedLine and Cinahl, in May 2007. Their search terms included "pharmaceutical industry," "drug sales," "directto-consumer," and "gift."

Their analysis included all articles that referred to nursing's relationship to drug companies and those that included the views of the industry on this issue; 32 articles met the inclusion criteria.

Thirteen of the articles expressed concern about the role of the industry, but the rest were ambivalent or positive about industry involvement.

One opinion piece in a nursing economics journal praised direct to consumer advertising as an antidote to what the article called doctors' "reluctance to share information."

Three articles encouraged healthcare professionals to work with the drug industry to promote accurate information for patients.

An editorial in one nursing journal started by acknowledging and appreciating the industry's support of nurse practitioners but then criticised the industry for failing to court nurse practitioners or to make reference to them in direct to consumer advertising as they do doctors.

Some articles, including those written by journal editors, even suggest that gifts from drug company representatives up to the value of $£ 50$ (€70; \$100) are acceptable. 


\section{Inquiry finds scientists collaborated with Nazis}

\section{Annette Tuffs HEIDELBERG}

A seven year investigation into the work of Germany's largest organisation that funds research has confirmed that German scientists used the Nazis' totalitarian regime to conduct lethal experiments.

The German research foundation (Deutsche Forschungsgemeinschaft) remains the country's largest funder of research, with an annual budget of about $€ 1.3 \mathrm{bn}$ (£970m; \$1.9bn). The independent investigation found that the organisation and most of the scientists it funded had succumbed to serving the Nazi regime "almost completely and without scruple" after its rise to power in 1933.

This started with the expulsion of Jewish and other scientists not in political favour from the foundation and from German universities. And it escalated to the experiments on Jewish prisoners conducted by Josef Mengele at Auschwitz, which were supported financially by the foundation.

Reporting the findings of the seven year investigation at a conference last week in Berlin, Matthias Kleiner, president of the foundation, said, "This is a profoundly uncomfortable and lasting truth for the foundation, very oppressive and very painful." The conference reviewed findings from an independent research unit set up by the foundation in 2001 after several previous attempts to analyse and acknowledge its history had failed.

The research unit systematically studied the history of the foundation from 1920 to 1970 , led by historians from Berlin and Freiburg. It reported that the foundation was set up in 1920 in an effort to improve the standard of science in Germany after the crisis resulting from the first world war. The investigation found that the close connection between science and politics had its roots in this period, when German scientists saw it as their duty to support national interests through their work.

After 1933, research funding was abused by the politicians of the Third Reich. In addition, the scientific community and politicians worked together

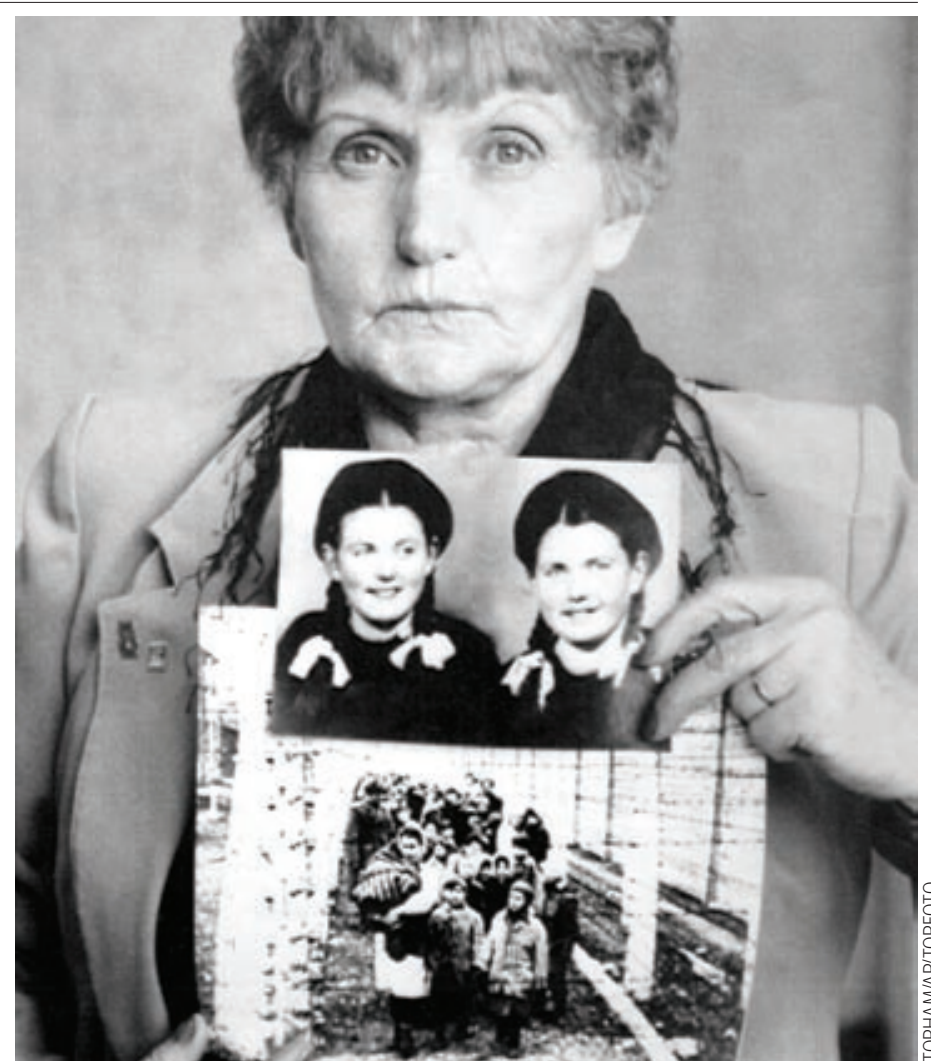

Eva Kor, a survivor of Mengele's experiments, holds a photo of her and her twin

to further each other's aims in a symbiotic partnership, according to one of the investigating historians, Mitchel Ash, from the University of Vienna, Austria. He explained that scientists sought personal advantage by participating in research projects and by anticipating programmes likely to be popular with the regime.

Medical research projects funded by the foundation at this time focused mainly on human genetics, supporting the Nazis' racist ideology. "The scientists clearly used the totalitarian system to have the freedom of conducting lethal experiments," said Wolfgang Eckart, medical historian from Heidelberg University. See http://projekte.geschichte.unifreiburg.de/DFG-Geschichte.

\section{Doctor-population ratio grew rapidly in UK from 2000}

\section{Susan Mayor LONDON}

The number of doctors in the United Kingdom grew more quickly than in other European countries in the first five years of this century, but the ratio of doctors to the population still remains lower than in many of them.

The ratio rose from two doctors per 1000 people in 2000-1 to 2.4 in 2005-6, but it was still only two thirds the ratio in France, Germany, or Italy.

The figures, published by the Office of Health Economics, also show that the total number of inpatients and patients treated as day cases in NHS hospitals in the UK grew by more than $15 \%$ in the same five years. The number was 17.1 million in 2005-6, 15\% higher than in 2000-1.
These figures were measured as finished consultant episodes or discharges (periods of care spent under one consultant in one NHS trust) in England and as hospital discharges and deaths in Wales, Scotland, and Northern Ireland. More than four fifths ( $81 \%$ ) of hospital inpatient admissions in Great Britain were for acute medicine or surgery. The ratio of finished consultant episodes, hospital discharges, and deaths per hospital bed continued to rise each year, reaching 76 per bed in 2005-6, a figure 10 times that of 50 years earlier.

The number of available beds in acute NHS hospitals has changed little for more than a decade and remains low by international standards at 2.2 beds per 1000 people in Great Britain.
The higher number of patients treated per hospital bed was accounted for by a continuing decrease in the average length of hospital stay in all specialties apart from mental illness and learning disabilities. The average stay was 4.4 days in 2005-6.

The total number of outpatient attendances at NHS hospitals grew to more than 81 million in 2005-6, an increase of $20 \%$ over the past 10 years. Most of this increase was due to growth in the number of first attendances, which rose by $35 \%$ over the five years.

The number of NHS hospital and community health staff rose by $23 \%$ from 2000-1 to 2005-6, to more than 1.2 million, the highest ever number. The 2008 Compendium of Health Statistics is available at www.OHEcompendium.org. 